Article

\title{
What Motivates Farmers' Adaptation to Climate Change? The Case of Apple Farmers of Shaanxi in China
}

\author{
Xiaolong Feng, Mingyue Liu, Xuexi Huo * and Wanglin Ma \\ College of Economics and Management, Northwest Agriculture and Forestry University, Yangling 712100, \\ China; fengxiaolong@nwafu.edu.cn (X.F.); liumingyue327@163.com (M.L.); mawanglin94@gmail.com (W.M.) \\ * Correspondence: xuexihuo@nwafu.edu.cn; Tel.: +86-29-8708-0157
}

Academic Editors: Hongbo Liu, Sizhong Sun and Iain Gordon

Received: 21 November 2016; Accepted: 27 March 2017; Published: 29 March 2017

\begin{abstract}
Past studies showing that barriers to farmers' adaptation behaviors are focused on their socio-economic factors and resource availability. Meanwhile, psychological and social considerations are sparingly mentioned, especially for the related studies in developing countries. This study investigates the impact of psychological factors and social appraisal on farmers' behavioral intention to adopt adaptation measures for the aforementioned reason, due to climate change and not to anthropogenic climate change. Drawing on the protection motivation theory, a threat, coping, social appraisal, maladaptation and behavioral intention to adopt adaptation measures (TCSMBI) model was proposed to predict farmers' adaptation. A structural equation model was then employed to analyze the relationships between variables in the TCSMBI model with 658 apple farmers in Shaanxi province, China. The empirical results showed that threat appraisal and coping appraisal have positive and significant impacts on behavioral intention to climate change. Moreover, threat appraisal reduces the occurrence of maladaptation, and social appraisal tends to have significantly positive impacts on threat appraisal and coping appraisal.
\end{abstract}

Keywords: adaptation; protection motivation theory; structural equation model; apple farmers; climate change; China

\section{Introduction}

Climate change has affected all sectors and levels of society in the world. To cope with the consequences of climate change, individuals, communities and even countries must seek useful and effective adaptation strategies [1]. Adaptation to climate change, especially in developing countries, is vital and has been highlighted as a high or urgent priority [2]. Agriculture is inherently sensitive to climate conditions, and is among the most vulnerable sectors to the impacts of global climate change [3-5]. As a result, adaptation to climate change in agriculture has become an important research issue in recent years [6]. In China, rain-fed agriculture is the dominant source of food production, employment and income for the majority of the rural people. However, due to global climate change, farmers are facing challenges to benefiting from agricultural production. Therefore, it is important to understand farmers' adaptation to climate change, which can help the government design appropriate policies to strengthen farmers' adaptive capacity.

Adaptation to climate change has generally been defined as an adjustment in response to reduce the impact of climate change on the farming operation, livelihoods, and people's lives [7-9]. Agricultural adaptation options are grouped according to four main categories that are not mutually exclusive [5]: technological developments such as developing new crop varieties, developing early warning systems and developing water management innovations [5], government programs and 
insurance such as developing crop insurance programs, modifying subsidy and incentive programs [5], changes to farm production practices such as diversifying crop or livestock types and varieties, changing timing of farm operations and changing the way irrigation $[5,10]$, and changes to farm financial management such as diversifying sources of household income [5,10-12] and purchasing crop insurance [5]. The last two categories mainly involve farm-level decision-making by farmers and are called autonomous adaptations, mostly referring to the coping measures of individual farmers and other stakeholders in farming activities [13]. Changes in practices at the farm level are of elementary importance in effective agricultural adaptation to climate change [14]. Therefore, the adaptation measures discussed in this paper are basically autonomous adaptation.

There have been numerous studies from researchers across different disciplines investigating determining factors that affect farmers' adaptation behaviors to climate change in agriculture [10,15-20]. Most of them have been conducted in developing countries where agriculture plays an essential role. According to their results, barriers to farmers' perception of climate change and adaptation have been almost exclusively restricted to their socio-economic factors and resource constraints, such as lack of access to credit, land and information, lack of knowledge on adaptation, lack of access to extension services like a local department of technical extension, or shortage of water resources [16-20].

Although these studies have their advantages in partially explaining farmers' decision-making mechanisms for adaptation behaviors, psychological barriers to farmers' adaptation so far have been mostly neglected, especially in developing countries [21,22]. Only a few researchers have begun to be concerned about the influence of psychological factors on farmers' behavioral intention to adopt adaptation measures. Grothmann and Patt [7] built a socio-cognitive model to understand individual behavioral intention to adopt adaptation measures based on protection motivation theory (PMT), examined this model through two case studies, one from urban Germany and one from rural Zimbabwe, and concluded this model is a good tool to explain private adaptation to climate change. After that, there were several studies applying PMT to understand individual behavioral intention to adopt adaptation measures to climate change [22-24]. Therefore, PMT has been demonstrated to be useful in explaining the influence of psychological factors on individual behavioral intention to adopt adaptation measures. However, studies applying PMT to analyze farmers' adaptation to climate change in the context of China are non-existent.

Additionally, Truelove et al. [24] pointed out that agricultural practices are social in nature in developing economies. That means that in order to determine the existence and effectiveness of new agricultural technologies, farmers communicate with others within their social network to strengthen their perception of these technologies or practices, and then adopt them to improve their behaviors [25]. Below et al. [21] showed that strengthening of social capital is one of the best means of improving farmers' adaptation to climate change in Tanzania. After that, others also indicated that social networks or social capital were found to significantly influence farmers' adaptation behaviors [13,26,27]. Accordingly, social appraisal is a vital factor affecting farmers' adaptation behaviors regarding climate change in developing countries, but it has been neglected by most studies. Although Truelove et al. [24] integrated social appraisal into PMT to predict paddy farmers' behavioral intention to adopt adaptation measures, they did not consider the relationships between social appraisal and the main variables in PMT, which decreases the validity of the model. As opposd to previous studies, we consider the influence of social appraisal on other main variables of PMT and farmers' adaptation in developing countries, especially in China.

This paper attempts to contribute to the literature by investigating how psychological factors and social appraisal influence farmers' adaptation to climate change. We employ protection motivation theory (PMT) to build up the conceptual framework. Due to lack of application of PMT in China, testing the applicability of the integrated conceptual framework to climate change in Chinese cultural setting is one of the innovations of our research. For this purpose, we focus our attention on apple farmers' behavioral intention to adopt adaptation measures in Shaanxi province, China. In particular, we narrow our focus to on-farm adaptation measures adopted by apple farmers, and the study uses 
data from the structured interviews with 658 apple farmers from eight counties in Shaanxi province, China. The purpose is to gain a greater understanding of apple farmers' adaptation to climate change in China.

Following the introduction, the rest of this paper is organized as follows: a conceptual framework of farmers' adaptation is presented in Section 2 followed by a description of the study materials and methods in Section 3. Discussion of estimation procedure and analysis of empirical results can be found in Section 4. Concluding remarks are contained in Section 5.

\section{Conceptual Framework}

PMT was originally introduced by Rogers in 1975, as an important theory in social cognitive of protective behaviors. Since then, there have been many studies applying this theory to understand and predict protective behaviors in the context of health risk [28-30], water conservation [31] and nuclear war [32]. Beyond these issues, PMT has been used for natural hazards [22,33-35], and climate change $[7,23,24]$. Hence, it is a key, effective theory that can deal with different threats within the domain of psychological research [23].

In the past few decades, a few studies have applied and extended PMT to analyze farmers' behavioral intention to adopt adaptation measures to climate change $[7,22,24,26]$. Accordingly, there are four major variables in PMT, including threat appraisal, coping appraisal, maladaptation and protection motivation $[22,23,28]$. Threat appraisal concerns the process of estimating the threat of climate change: the likelihood of climate change occurring (perceived probability) and the severity should it occur (perceived severity) [23]. If the threat of climate change is deemed to be high risk, people intent to protect themselves from the threat (in this case reduce the occurrence of maladaptation and adopt adaptation measures).

In the coping appraisal, people evaluate their perceived ability to undertake adaptation measures (perceived self-efficacy; [22,24], as well as the perceived effectiveness of adaptation measures in preventing the threatened risk (perceived response efficacy; [22,24]). If individual farmers feel capable of coping with the threat and believe that new measures will be effective to adapt to climate change, they will intend to take protective actions and reduce the occurrence of maladaptation [23]. After threat appraisal and coping appraisal of climate change, people may choose maladaptation (i.e., fatalism, denial and wishful thinking) or come up with behavioral intention to adopt adaptation measures. Farmers' fatalism, wishful thinking, and the denials of climate change risk may hinder their intention to adapt.

However, agricultural practices in many developing countries are social in nature and the current extensions of PMT do not fully capture these dynamics [24]. In production practice, farmers usually determine the existence and effectiveness of new agricultural technologies by communicating with others within their social network [25]. Such a network essentially provides informal communication channels, which farmers employ to receive and share information on new technologies or practices [36], as well as to learn individual productive behaviors [37]. As a result, numerous empirical studies demonstrated that social networks do significantly influences the adoption decision of individual farmers [36-40]. Additionally, Sherchan et al. [41] pointed out that the success of a social network for an individual relies on the level of trust between himself and other members in the same community. Without social trust, members may not feel comfortable expressing their opinions [42], which is makes it harder for individuals to receive and share information within their social network.

These related studies on social networks and social trust provide a meaningful reference to understand further farmers' adaptation to climate change in developing countries. Based on these research results, social factors including social capital or social network were considered by several studies to explain farmers' adaptation to climate change. For Tanzanian farmers, social capital was a significant predictor of agricultural adaptation [21]. Esham and Garforth [13] extended the "social networking" into PMT model to the study of farmers' adaptation to climate change in Sri Lanka. They included an item assessing "social networking", which was operationalized as how often the individual 
discusses climate change and adaptation measures with other farmers. Results indicated that farmers who more often communicate the information about climate change and adaptation measures with others adopt more adaptation measures by themselves. This is one of the first interesting findings to suggest that integrating a social element into the PMT may be useful to understand farmers' adaptation behaviors. In addition, Truelove et al. [24] also integrated social appraisal and PMT into their theoretical framework, and found that farmers' social appraisal positively predicts behavioral intention to adopt adaptation measures. As he noted, in Sri Lanka, farmers who interact with others, especially with his community (including community attachment, organization membership, and trust) as well as his perception of group norms surrounding adaptation measures are more likely to intend to adopt adaptation measures [24].

These recent findings illustrate that he potential exists for including the social considerations in models of farmers' adaptation to climate change. Building on these existing works, we propose an extension of PMT that is more applicable to obtain a better understanding of farmers' behavioral intention to adopt adaptation measures to climate change. In the threat appraisal, coping appraisal, social appraisal, maladaptation and behavioral intention to adopt adaptation measures model (TCSMBI), we include social appraisal as a predictor of farmers' adaptation. In this study, social appraisal represents the extent to which an individual farmer identifies with members in his communities or villages including relationship of communication (intensity of communication) and trust (intensity of trust) with others, as well as how his learning effects surrounding adaptation behaviors from others. Farmers who tend to discuss adaptation measures to climate change and have strong trust relationships with other individuals within their social network, as well as those who learn how farmers' behaviors change in response to climate change in their surroundings, will rate climate change as a serious threat, will feel capable of coping with the threat with the belief of the effectiveness of adaptation measures, and will be more likely to intend to and later adopt adaptation measures to climate change. Based on the above analysis, the interaction between these five variables can be expressed as shown in Figure 1. The objective of this paper is to examine the utility of the TCSMBI model in analyzing farmers' behavioral intention to adopt adaptation measures to climate change in China.

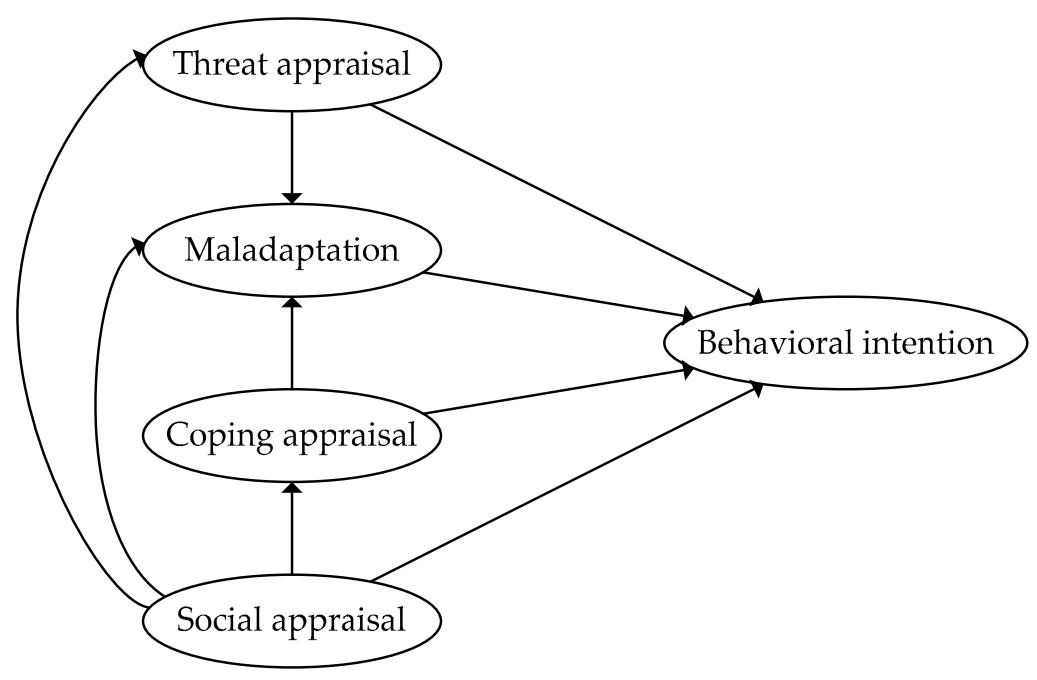

Figure 1. Path diagram of the threat appraisal, coping appraisal, social appraisal, maladaptation and behavioral intention (TCSMBI) model. 


\section{Materials and Methods}

\subsection{Research Site}

Climate change and its impact vary from region to region [43], so we choose only one region, Shaanxi province in the central of China, as our research site (Figure 2). Shaanxi locates between $31.42^{\circ} \mathrm{N}-39.35^{\circ} \mathrm{N}$ latitude and $105.29^{\circ} \mathrm{W}-111.15^{\circ} \mathrm{W}$ longitude. It covers a total land area of 205,800 square $\mathrm{km}$, and nearly $40 \%$ is in the region of loess plateau (wind deposited, lack of vegetation cover and susceptible to wind and water erosion) that mostly lie in the north [44]. The altitude ranges from 350 to $3500 \mathrm{~m}$ above sea level. This province is divided into three parts according to the administrative zone: Shaanbei Plateau in the north, Guanzhong Plain in the central, and Qinling-Dabashan Mountains in the south. Due to specific physiographic features and climate conditions in Shaanbei Plateau and Guanzhong Plain, Shaanxi has become one of the most suitable regions for apple production in the world, with more than 30 counties in which local governments regard apple industry as a dominant industry in developing the rural economy. According to the statistical data, the area of apple growing in Shaanxi province in 2013 reached 665, 200 hectares, accounting for $27.60 \%$ of the area in China and $12.75 \%$ in the world (FAO). Apple production is the dominant source of family income for the majority of smallholder farmers in this province, accounting for $71.38 \%$ of total family income in Shaanxi province according to survey data.

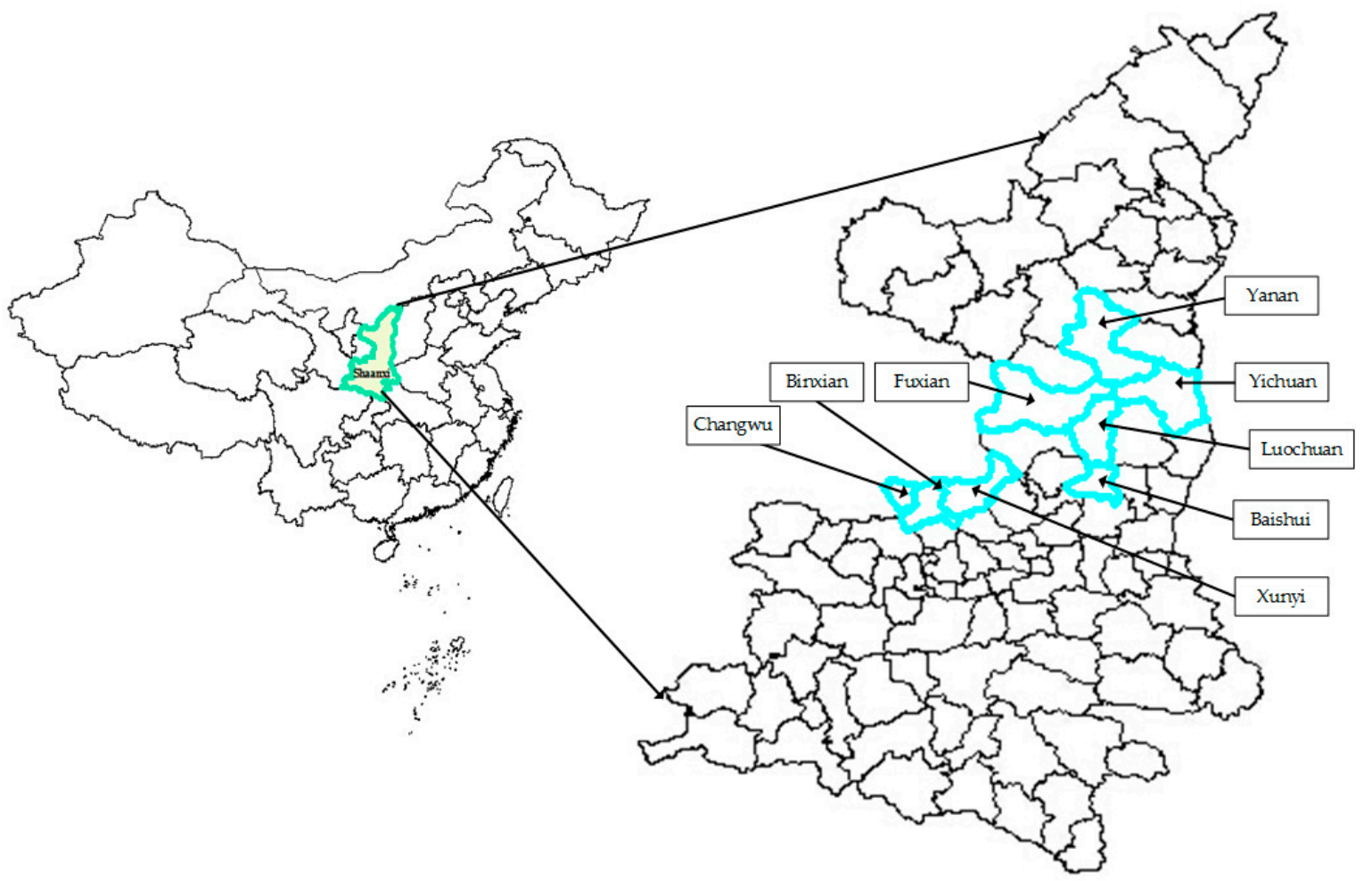

Figure 2. Shaanxi province and surveyed locations.

The region has been identified as significantly vulnerable to climate change [44]. Regional climate data suggest the temperature has warmed by about $1.4{ }^{\circ} \mathrm{C}$ over the past 30 years, and future warm is continuing. Meanwhile, the magnitude of precipitation has declined by about $15 \%$ in recent decades, and continued reductions are projected in the future [44]. These characteristics of climate change have a serious influence on apple production, which results in the fluctuation of individual farm households' income in this region. Therefore, understanding why apple farmers in this region are 
likely to undertake adaptation measures is vital to strengthen their adaptive capacity to climate change. Based on this information, Shaanxi province was selected purposefully to the focus of the study.

\subsection{Sampling and Data Collection}

The research design was based on multi-stage sampling techniques to collect the samples. In the first stage, eight counties including Yanan, Fuxian, Yichuan, Luochuan, Baishui, Changwu, Binxian and Xunyi were randomly selected from 30 major apple-producing counties based on the intensity of apple production (Figure 2). In the second stage, 5 villages in each selected county were randomly selected. In the third stage, random sampling techniques were used to collect the sample of smallholder farmers and around 15-20 households in each village were randomly selected. A sample frame acquired from the local apple sector was used to sample the required number of farmers from each village.

Face-to-face interviews were conducted during July and August 2015 by the authors and 14 interviewers who had been trained in two intensive training sessions, one before and one after the questionnaire's pre-test. The interviewees were household heads and their spouses. To be eligible for interview, farmers must have grown apples for at least 10 years and heard about climate change in this region. A short definition of climate change and its interpretations were introduced to apple farmers before questions were asked. The interviewers visited 663 farm households, but 5 were not eligible for interview because of lack of major information. Thus, the final sample size was 658 completed questionnaires.

To collect the required data, a structured questionnaire was adopted that included 5 sections: farmers' perceptions of climate change (perceived probability and severity), coping appraisal, social appraisal, behavioral intention to adopt adaptation measures and their demographic and economic backgrounds. The selection of explanatory variables was mainly developed from the frameworks of Dang et al. [23], Grothmann and Patt [7] and Truelove et al. [24], and refined. In order to ensure its clarity and relevance, the questionnaire was pre-tested with 40 randomly selected apple farmers' households in this province.

\subsection{Variable Measurements}

Threat appraisal, coping appraisal, social appraisal and maladaptation are used as independent variables, and behavioral intention to adopt adaptation measures is used as a dependent variable in this study. The structural equation model (SEM) was used to estimate the interrelationships among five variables in the conceptual model. The following parts introduce how five variables are measured by observed indicators (see Table 1).

Threat appraisal of climate change mainly includes perceived probability and perceived severity in the PMT measures $[7,23,35,45]$. Perceived probability is defined as "people's expectation of the likelihood of the threat occurring" [24]. In this study, perceived probability was measured by asking apple farmers to rate to what extent they agreed with corresponding statements based on 5-point Likert scales ( $1=$ strongly disagree to $5=$ strongly agree). The three statements were "average temperature in recent five years has increased", "average precipitation in recent five years has declined", and "climate during different stages of the apple growing season (pre-flowering stage (January-March), flowering, fruit-set and fruit developmental stage (April-June), fruit developmental stage (July-September) and post-harvest stage (October-December)) has obviously changed in the last five years". Perceived severity refers to the level of damage that people expect to bear if climate change is realized [26]. Accordingly, perceived severity of climate change was measured in five dimensions of farmers' lives and apple production: family income, production investments like fertilizer and pesticide investments, apple growing, apple yield and quality. Individual apple farmers were asked to respond to the statement "climate change has a serious influence on your family or your apple growing" on a 5-point Likert scale $(1=$ strongly disagree to $5=$ strongly agree). These five items were used to build a composite measure of perceived severity. 
Table 1. Observed indicators of variables in the model.

\begin{tabular}{|c|c|c|c|}
\hline Item & Description & Coding & Variables \\
\hline TA1 & Perceived probability & \multirow{2}{*}{$\begin{array}{l}\text { 5-point Likert scale } \\
\text { (disagree to agree) }\end{array}$} & \multirow{2}{*}{ Threat appraisal } \\
\hline TA2 & Perceived severity & & \\
\hline CA1 & Perceived response efficacy & $\begin{array}{l}\text { 5-point Likert scale } \\
\text { (not effective to effective) }\end{array}$ & \multirow{2}{*}{ Coping appraisal } \\
\hline CA2 & Perceived self-efficacy & $\begin{array}{l}\text { 5-point Likert scale } \\
\text { (disagree to agree) }\end{array}$ & \\
\hline M1 & $\begin{array}{l}\text { There is no need to adapt because the } \\
\text { influences of climate change on your } \\
\text { life and apple production are light }\end{array}$ & \multirow{3}{*}{$\begin{array}{l}\text { 5-point Likert scale } \\
\text { (disagree to agree) }\end{array}$} & \multirow{3}{*}{ Maladaptation } \\
\hline M2 & $\begin{array}{l}\text { It is not necessary to take adaptation } \\
\text { measures since they do not work well }\end{array}$ & & \\
\hline M3 & Everything is decided by fate & & \\
\hline SA1 & Intensity of communication & $\begin{array}{l}\text { 5-point Likert scale } \\
\text { (not at all to very often) }\end{array}$ & \multirow{3}{*}{ Social appraisal } \\
\hline SA2 & Intensity of trust & \multirow{2}{*}{$\begin{array}{l}\text { 5-point Likert scale } \\
\text { (disagree to agree) }\end{array}$} & \\
\hline SA3 & Learning effects & & \\
\hline BI1 & Changing timing of irrigation & \multirow{8}{*}{$\begin{array}{l}\text { To what extent the } \\
\text { behavioral intention is on a } \\
\text { 5-point Likert scale (not at } \\
\text { all to very large extent) }\end{array}$} & \multirow{8}{*}{ Behavioral intention } \\
\hline BI2 & Changing timing of fertilizer & & \\
\hline BI3 & Changing timing of pesticides & & \\
\hline BI4 & Diversifying the apple varieties & & \\
\hline $\mathrm{BI} 5$ & Using artificial grass in apple orchards & & \\
\hline BI6 & $\begin{array}{l}\text { Covering black plastic film mulch in } \\
\text { apple orchards }\end{array}$ & & \\
\hline BI7 & $\begin{array}{l}\text { Investing in water storage in } \\
\text { apple orchards }\end{array}$ & & \\
\hline BI8 & Diversifying income sources & & \\
\hline
\end{tabular}

Perceived response efficacy and perceived self-efficacy are the main efficacy items comprising the coping appraisal process $[22,24,45,46]$. Perceived response efficacy is defined as "the belief about whether a proposed coping response will be perceived to be effective in reducing threat to the individual" $[22,28]$. Accordingly, respondents were asked to rate the effectiveness of adaptation measures to climate change by asking "how effective are the measures at helping to reduce the impact of climate change on your apple production and your family life?" Consequently, 8 adaptation measures were presented and each item was anchored by $1=$ not at all effective to $5=$ very effective. These 8 adaptation measures are detailed in the next section. These 8 measures were combined into a composite measure of perceived response efficacy. Similarly, perceived self-efficacy is defined as "the perceived ability of the person to carry out adaptation measures" [22,47]. The measurements of self-efficacy were developed based on measuring how confident respondents felt about their ability to protect their agricultural production from climate change [22]. In this study, individual apple farmers were asked "you are confident about taking the following 8 adaptation measures to reduce the impact of climate change" based on 5-point Likert scale ( $1=$ strongly disagree to $5=$ strongly agree).

Grothmann and Patt [7] mentioned that individuals' maladaptation responses include denial of the threat of climate change, wishful thinking and fatalism. It is believed that farmers are less likely to adapt when they are subject to wishful thinking, denials of climate change risk, and fatalism [23]. Thus, maladaptation was measured by asking apple farmers to response to what extent they agreed with corresponding three statements based on 5-point Likert scales $(1=$ strongly disagree to $5=$ strongly 
agree). The three statements were "there is no need to adapt because the influence of climate change on your life and apple production is small", "it is not necessary to take adaptation measures since they do not work well", and "everything is decided by fate".

Based on the above analysis in Section 2, social appraisal includes the intensity of communication and trust with others, and learning effects from other members in individuals' communities. According to Esham and Garforth [13], Truelove et al. [24] and Wang and Lu [48], three components were measured as follow. The intensity of communication were measured by asking apple farmers to rate to what extent they communicated in their communities with corresponding three statements based on 5-point Likert scales ( $1=$ not at all to $5=$ very often). The three statements about intensity of communication were "how often do you communicate about climate change and adaptation measures on apple production with other farmers", "how often do you communicate about adaptation measures on apple production with staff in local extension department related to apple industry", "how often do you communicate about adaptation measures on apple production with experts in apple's technical training courses". The intensity of trust was measured by asking apple farmers to rate to what extent they agreed with corresponding statements based on 5-point Likert scales from 1 (strongly disagree) to 5 (strongly agree). The three statements were as follow: "you think that you can trust farmers in your community or village when you communicate with them", "you often borrow something to the villagers", "you believe all kinds of information from your village committee, especially the information related to apple". Similarly, the measuring statements of learning effects were "When you see someone in your community or village adopts adaptation measures to climate change, you will also adopt", "the more farmers adopt adaptation measures, the more you will adopt", "you adopt adaptation measures because of the suggestions from others in your community or village", "when you see that the effect of one measure is pretty good, you will take with no hesitation" on a 5-point Likert scale $(1=$ strongly disagree to $5=$ strongly agree).

The dependent variable is apple farmers' behavioral intention to adopt adaptation measures. According to past research about this issue, farmers have a variety of measures to deal with unexpected losses in agricultural production associate with climate change, include adjusting production practices, water management, crop diversification, diversifying income sources, and participating in risk-reduction policies [5,18,22-24]. In addition to these measures mentioned by past studies, apple farmers also take several other specific measures to adapt to climate change due to the perennial characteristics of apple growing, such as using artificial grass in apple orchards, covering black plastic film mulch in apple orchards, and investing in water storage in apple orchards [49,50].

Combining the conclusions of past these studies and characteristics of apple growing, 8 adaptation measures for reducing the effects of climate change on apple production were included in this study: changing timing of irrigation, changing timing of fertilizer, changing timing of pesticides, diversifying the apple varieties, using artificial grass in apple orchards, covering black plastic film mulch in apple orchards, investing in water storage in apple orchards, and diversifying income sources $[49,50]$. In practice, behavioral intention of adaptation against climate change was measured by asking apple-producing farmers to rate what extent they intended to adopt each adaptation measure. These were measured using a 5 -point Likert scale $(1=$ not at all to $5=$ very large extent). The 8 adaptation measures were combined into a composite measure of behavioral intention.

The maximum livelihood estimation was run to solve this SEM of apple farmers' adaptation by IBM SPSS Amos 22. The estimation of SEM included two procedures: evaluate the validity of the measurement model and test the structure model $[23,51]$. In the first procedure, confirmatory factor analysis (CFA) was run. Two criteria for assessing the validity of the measurement model are the acceptable levels of goodness-of-fit (GOF) and construct validity [52]. Although different studies reported Chi-square test and other various GOF indices [23,51,53], there are several goodness-of-fit indices commonly used, including root mean square error of approximation (RMSEA), comparative fit index (CFI), goodness-of-fit index (GFI), normed fit index (NFI), and normed Chi-square ( $\left.\chi^{2} / \mathrm{df}\right)$ [54]. Besides, in order to get the value of construct validity, three indicators need to be calculated: 
standardized factor loadings, average variance extracted (AVE) and construct reliability (CR) [23]. In the second procedure, SEM was tested on GOF indices with the same assessment criteria in CFA, followed by the interpretation of path coefficients, direct, indirect and total effects.

\section{Results and Discussion}

\subsection{The Measurement Model}

This study uses 658 observations to conduct the CFA. Accordingly, the goodness-of-fit indices for the measurement model are $\chi^{2}=190.707, \mathrm{df}=104, p=0.000, \mathrm{CFI}=0.984$, GFI $=0.969$, $\mathrm{NFI}=0.965$, RMSEA $=0.036$ and normed $\chi^{2}=1.834$. The $p$-value was less than $0.01(1 \%$ significant level), so the null hypothesis that the observed and estimated covariance matrices are equal was rejected. However, if the number of sample observations is higher than 250, a significance $p$-value is normally expected [52]. The good fit level of CFI, GFI and NFI is commonly at 0.95 and 0.90, respectively [54]. RMSEA is acceptable between 0.03 and 0.08 and normed Chi-square equal or less than 3 is associated with better fit [52]. All goodness-of-fit indices show a good fit, and thus it can be concluded that there is a relatively good fit between the measurement model and the sample data.

In addition to these indices, factor loadings, CR and AVE of construct also are required in the model. Standardized factor loadings should be at least 0.5 , and statistically significant. They contribute to calculating the construct validity [52]. In our model, all standardized factor loadings are statistically significant, and most of them are above 0.5 except several values at a lower level (Table 2). CR and AVE are two indicators of convergent validity of the model. CR at 0.6 or higher suggests good reliability, and an AVE of 0.5 or higher suggests adequate convergence [52]. In our model, the CR values for all constructs are higher than 0.6 , and thus these results suggest acceptable reliability. The AVE values for some constructs (threat appraisal, social appraisal) are at marginal levels and but the other respective indicators (i.e., CR and factor loadings) are at acceptable levels, which implies that the model has acceptable convergent validity in this study.

Table 2. Factor loadings, average variance extracted (AVE) and construct reliability (CR) in CFA.

\begin{tabular}{|c|c|c|c|c|}
\hline Variables & Items & Factor Loadings & AVE & CR \\
\hline \multirow{2}{*}{ Threat appraisal } & TA1 & $0.724^{\mathrm{a}}$ & \multirow[b]{2}{*}{0.453} & \multirow[b]{2}{*}{0.621} \\
\hline & $\mathrm{TA} 2$ & $0.599^{* * *}$ & & \\
\hline \multirow{2}{*}{ Coping appraisal } & CA1 & $0.766^{* * *}$ & \multirow{2}{*}{0.642} & \multirow{2}{*}{0.782} \\
\hline & CA2 & $0.835 \mathrm{a}$ & & \\
\hline \multirow{3}{*}{ Social appraisal } & SA1 & $0.713^{* * *}$ & \multirow{3}{*}{0.378} & \multirow{3}{*}{0.639} \\
\hline & SA2 & $0.642^{* * *}$ & & \\
\hline & SA3 & $0.461^{\mathrm{a}}$ & & \\
\hline \multirow{3}{*}{ Maladaptation } & M1 & $0.723^{* * *}$ & \multirow{3}{*}{0.518} & \multirow{3}{*}{0.76} \\
\hline & M2 & $0.821^{a}$ & & \\
\hline & M3 & $0.597 * * *$ & & \\
\hline \multirow{8}{*}{$\begin{array}{l}\text { Behavioral } \\
\text { intention }\end{array}$} & BI1 & $0.846^{\mathrm{a}}$ & \multirow{8}{*}{0.495} & \multirow{8}{*}{0.878} \\
\hline & $\mathrm{BI} 2$ & $0.729^{* * *}$ & & \\
\hline & $\mathrm{BI} 3$ & $0.646^{* * *}$ & & \\
\hline & BI4 & $0.812 * * *$ & & \\
\hline & BI5 & $0.798^{* * *}$ & & \\
\hline & BI6 & $0.795^{* * *}$ & & \\
\hline & $\mathrm{BI} 7$ & $0.584^{* * *}$ & & \\
\hline & BI8 & $0.176^{* * *}$ & & \\
\hline
\end{tabular}

$\overline{\text { Note: }}{ }^{* * *}$ significant at $1 \%$. ${ }^{\text {V Values were not calculated because loadings were set to } 1.0 \text { to control construct variance. }}$ 


\subsection{Hypotheses Testing}

The structural model was tested next. The goodness-of-fit indices $\left(\chi^{2}=198.936, \mathrm{df}=105\right.$, $\mathrm{CFI}=0.982$, GFI $=0.968, \mathrm{NFI}=0.964$, RMSEA $=0.037$ and normed $\left.\chi^{2}=1.895\right)$ support the appropriateness of the structural model. Table 3 presents standardized path coefficients resulting from testing the proposed structural model. Most structural path coefficients were significant (support was found for five of the nine hypothesized paths) and the signs of structural paths coefficients were consistent with the hypothesized relationships. The squared multiple correlation $\left(R^{2}\right)$ is $60.4 \%$ for the dependent variable, behavioral intention to adopt adaptation measures. That means over $60.4 \%$ variation of behavioral intention can be explained by the significant independent variables in the TCSMBI model. Figure 3 shows the results of hypothesis testing.

Table 3. Standardized coefficient estimates of the structural model.

\begin{tabular}{cccc}
\hline Paths & Estimates & S.E. & $t$-Value \\
\hline H1: Threat appraisal $\rightarrow$ Behavioral intention & 0.244 & 0.170 & $2.979 * * *$ \\
H2: Threat appraisal $\rightarrow$ Maladaptation & -0.454 & 0.338 & $-4.187^{* * *}$ \\
H3: Coping appraisal $\rightarrow$ Behavioral intention & 0.720 & 0.087 & $12.389^{* * *}$ \\
H4: Coping appraisal $\rightarrow$ Maladaptation & 0.015 & 0.142 & 0.229 \\
H5: Maladaptation $\rightarrow$ Behavioral intention & -0.047 & 0.033 & -0.946 \\
H6: Social appraisal $\rightarrow$ Threat appraisal & 0.410 & 0.106 & $4.124^{* * *}$ \\
H7: Social appraisal $\rightarrow$ Maladaptation & 0.082 & 0.291 & 0.942 \\
H8: Social appraisal $\rightarrow$ Coping appraisal & 0.571 & 0.119 & $7.136^{* * *}$ \\
H9: Social appraisal $\rightarrow$ Behavioral intention & -0.073 & 0.143 & -1.136 \\
Squared Multiple Correlation $\left(\mathrm{R}^{2}\right)$ & & & \\
Behavioral intention $=60.4 \%$ & & & \\
\hline
\end{tabular}

Note: ${ }^{* * *}$ significant at $1 \%$.

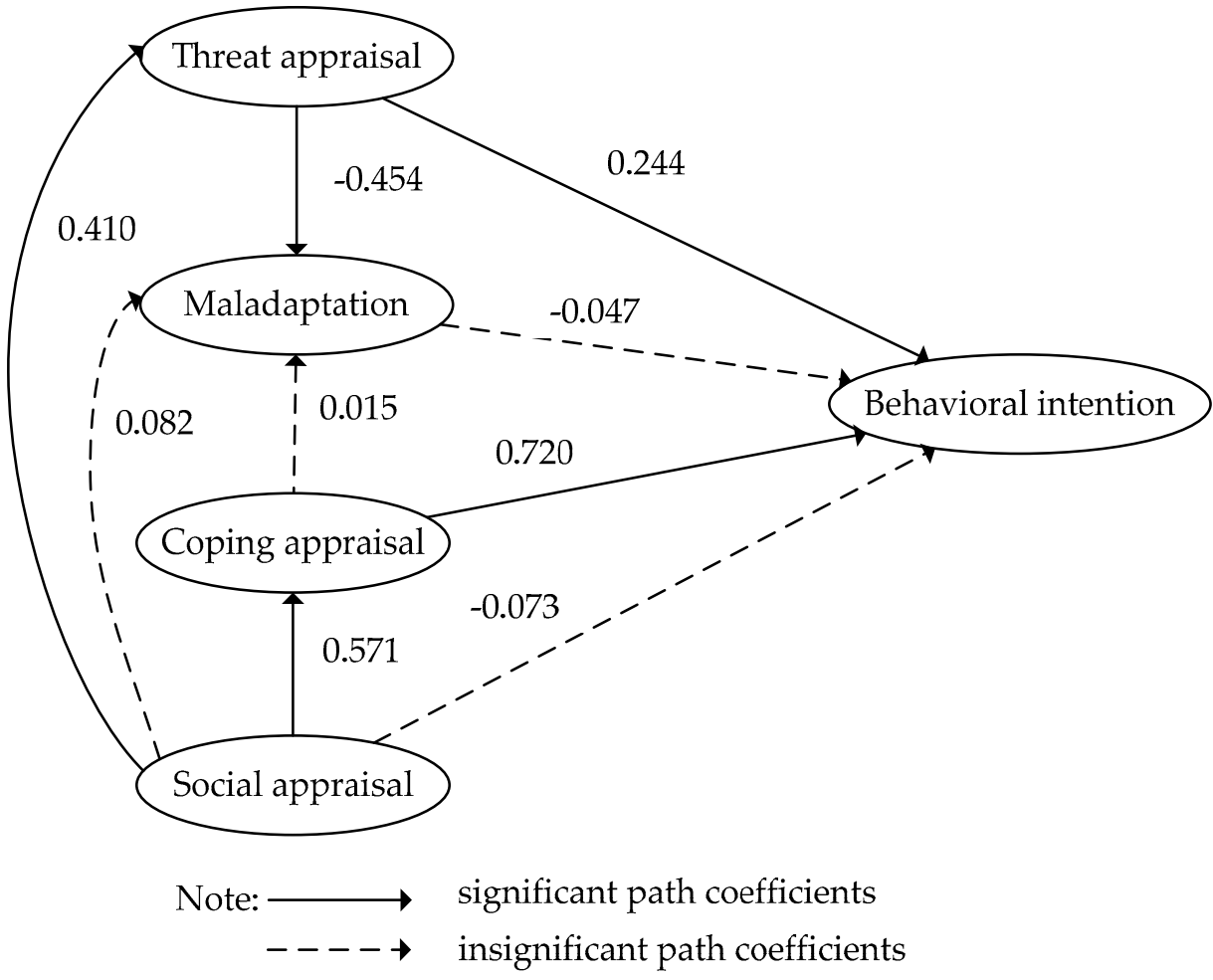

Figure 3. Results of the structural model. 
Accordingly, behavioral intention to adopt adaptation measures to climate change not due to anthropogenic climate change is significant positively affected by threat appraisal and coping appraisal ( $\mathrm{H} 1: \beta=0.244, t$-value $=2.979$ and $\mathrm{H} 3: \beta=0.720, t$-value $=12.389$, respectively) and is insignificantly negatively affected by maladaptation (H5: $\beta=-0.047$, $t$-value $=-0.946$ ). There is a significantly negative relationship between threat appraisal and maladaptation with the structural path estimate of -0.454 and a $t$-value of $-4.187(\mathrm{H} 2)$, while the relationship between coping appraisal and maladaptation is not significant $(\mathrm{H} 4: \beta=0.015$, $t$-value $=0.229)$. In addition, social appraisal has statistically significant effects on threat appraisal and coping appraisal with $\gamma=0.410$ and $t$-value $=4.124(\mathrm{H6})$, and $\gamma=0.571$ and $t$-value $=7.136(\mathrm{H} 7)$, respectively. However, the relationships between social appraisal, and maladaptation and behavioral intention respectively are not significant. The standardized coefficients are 0.082 (H8) and -0.073 (H9) (Table 3).

The empirical results of the structural model indicate that higher threat appraisal and coping appraisal would lead to higher levels of behavioral intention to adopt adaptation measures. This means that when apple farmers believe there is a higher likelihood of climate change are threatening their family income, production investments, apple growing, apple yield and quality, they are more likely to have a higher intention to adapt to climate change. Farmers' behavioral intention also increases when they perceive greater effectiveness of adaptation measures and greater ability to carry out adaptation measures. By contrast, farmers are less likely to intend to adapt when they are subject to wishful thinking, the denials of climate change risk, and fatalism. These results are consistent with the findings of Grothmann and Patt [7], Grothmann and Reusswig [34], and Dang et al. [23].

Moreover, the results show that higher threat appraisal to climate change would reduce the occurrence of farmers' maladaptation. Although this is not consistent with the point that climate change risk appraisal positively affects maladaptation [7], Dang et al. [23] found a significant and negative association between risks of climate change and maladaptation to farmers in Vietnam. This can be explained by the fact that many farmers have perceived the harmful influence of climate change on their lives and agricultural production, and then tend to take various adaptation measures directly, which results in only a small proportion of farmers being inclined to choose maladaptation when they are asked questions about climate change. Coping appraisal of adaptation measures does not statistically significantly affect maladaptation, but it has a positive relationship with behavioral intention to adopt adaptation measures. Dang et al. [23] similarly found coping adaptation assessment to be insignificant and positive in predicting intention to undertake adaptation measures.

The findings further indicate that farmers' higher social appraisal would significantly improve their threat appraisal to climate change and coping appraisal to adaptation measures. When farmers prefer to communicate information about climate change and adaptation measures with other individuals (e.g., friends, relatives, neighbors and even staff in extension services) in their surroundings, they may have a deep understanding to climate change and adaptation measures, which promotes them tend to believe that higher likelihood of climate change are threatening their family income and agricultural production, and perceive greater effectiveness of adaptation measures and stronger confidence to take adaptation measures, and then intend to adopt adaptation measures. Additionally, those who have a higher trust level with other individuals in their neighbors are more likely to intend to adopt adaptation measures, when they learn adaptation measures through observing neighboring farmers and attempt to imitate their behavioral change to climate change. In Sri Lanka, Esham and Garforth [13] similarly reported that social network significant positively affects farmers' adaptation as most adaptation measures are learned through experience and observing neighboring farmers. In contrast, social appraisal has an insignificant positive relationship with maladaptation, and a negative association with behavioral intention, which is inconsistent with the expected sign in conceptual framework. The result may be explained by the fact that many apple farmers have a low level of cognition about new-style adaptation measures such as using artificial grass in apple orchards, covering black plastic film mulch in apple orchards, and investing in water storage in apple orchards, 
whilst they have higher social appraisal, which results in decreasing behavioral intention to adopt adaptation measures to climate change.

The total effects of the structural equation model can be divided into direct and indirect effects on the basis of its inter-correlated relationships [55]. Direct effects of variables can be found in the results of standardized coefficient estimates of the structural model (Table 3). According to Bollen [56], an identification of indirect effects can help assess whether or not the secondary effects strengthen or moderate structural associations between the variables. Therefore, analyzing total, direct and indirect effects of variables can help us understand the interrelationships of variables more comprehensively (Table 4). The total effects between threat appraisal and coping appraisal, and behavioral intention are 0.265 and 0.719 , which are mainly contributed by direct relationships ( 0.244 and 0.720 , respectively). The effects of the direct structural path between social appraisal and behavioral intention is not significant and the coefficient is -0.073 , very small. But it is important to note that there is a significant and strong indirect effect between the two latent variables that are mediated by threat appraisal and coping appraisal. That is, social appraisal mainly contributes to threat appraisal and coping appraisal respectively, which in turn affect farmers' behavioral intention. The inclusion of this variable in PMT model can improve its interpretation to predict farmers' behavioral intention to adopt adaptation measures to climate change.

Table 4. Total, direct and indirect effects of variables.

\begin{tabular}{lccc}
\hline Variables Relationships & Total Effects & Direct Effects & Indirect Effects \\
\hline Threat appraisal $\rightarrow$ Behavioral intention & 0.265 & 0.244 & 0.021 \\
Coping appraisal $\rightarrow$ Behavioral intention & 0.719 & 0.720 & -0.001 \\
Social appraisal $\rightarrow$ Behavioral intention & 0.442 & -0.073 & 0.515 \\
\hline
\end{tabular}

Since farmers' behavioral intention to adopt adaptation measures to climate change is mainly directly affected by threat appraisal and coping appraisal, and indirectly influenced by social appraisal, some policy implications need to be considered. Threat appraisal and coping appraisal are influenced by information farmers receive about climate change and adaptation measures, whilst the information diffuses among farmers through their communication and learning in communities. Therefore, firstly, it is essential to ensure the accuracy and timeliness of the information that farmers obtain; secondly, it is very important to take advantage of farmers' social networks and learning effects on the spread of such information. According to our practical survey, many apple farmers lack the technical knowledge of adaptation measures, especially the new-style adaptation measures, which hinders farmers' intention to adapt to climate change. This suggests that agricultural extension services should strengthen communication with local farmers in different ways (information propagating, organizing technical training about climate change and adaptation measures, etc.), which help farmers understand the importance of adaptation and function of adaptation measures to climate change. Those who have taken measures to adapt should be regarded as role models and encouraged to share their good experiences in adapting to climate change with other farmers. Meanwhile, those who never take measures should be encouraged to learn the effective adaptation measures from others who they trust (e.g., farmers, agricultural extension services). Only in these ways can farmers improve their adaptive capacity to climate change.

Five of the nine path coefficients of the TCSMBI model, a PMT-based model of agricultural adaptation (threat appraisal, coping appraisal, social appraisal, maladaptation and behavioral intention), are found to be significant. Therefore, the TCSMBI model is a useful framework to explain the farmers' behavioral intention to adopt adaptation measures to climate change. However, like all studies, this study is not without limitations. One of limitations is that there may be grounds for questioning whether it is possible to elicit farmer's social appraisal from answers to standardized questions. This limitation should be kept in mind when evaluating the conclusions of our study. How 
to improve the construct validity in the measurement of farmers' social appraisal should be analyzed in future research.

\section{Conclusions}

According to the results of the structural equation model, the TCSMBI model is a useful framework to investigate farmers' behavioral intention to adopt adaptation measures to climate change in China. First, findings of this study prove that the PMT plays a significant role in predicting farmers' behavioral intention to adopt adaptation measures against climate change. The results show that threat appraisal and coping appraisal significantly and positively affect behavioral intention to adopt adaptation measures to climate change, whilst there is a significantly negative relationship between threat appraisal and maladaptation. Second, the empirical study provided clear evidence that social appraisal is also a significantly important factor influencing farmers' behavioral intention to adopt adaptation measures in developing countries. Accordingly, social appraisal has statistically significant effects on threat appraisal and coping appraisal while the relationship between social appraisal and behavioral intention is not significant. This means social appraisal mainly contributes to threat appraisal and coping appraisal, which in turn affect farmers' behavioral intention to adopt adaptation measures to climate change.

Acknowledgments: We would like to thank the China Agriculture Research System (CARS-28) and the Natural Science Foundation of China (71573211) for funding the research. We appreciate the constructive suggestions from peer reviewers and the help of editors. Special thanks to the 28th CESA Annual Conference at JCU Carins, Australia for helpful comments and suggestions from experts.

Author Contributions: Data collection, experimental design and data analysis were done by Xiaolong Feng and Mingyue Liu. The results interpretation were done by Xiaolong Feng, Xuexi Huo, and Wanglin Ma. All authors were committed to improving this paper and are responsible for the viewpoints mentioned in this work.

Conflicts of Interest: The authors declare no conflicts of interest.

\section{References}

1. Lim, B.; Spanger-Siegfried, E.; Burton, I. Adaptation Policy Frameworks for Climate Change: Developing Strategies, Policies and Measures; Cambridge University Press: Cambridge, UK, 2004.

2. United Nations Framework Convention on Climate Change (UNFCCC). Climate Change: Impacts, Vulnerabilities and Adaptation in Developing Countries; UNFCCC: Bonn, Germany, 2007.

3. Parry, M.L.; Carter, T.R. An assessment of the effects of climatic change on agriculture. Clim. Chang. 1989, 15, 95-116. [CrossRef]

4. Reilly, J. Climate change and global agriculture: Recent findings and issues. Am. J. Agric. Econ. 1995, 77, 727-733.

5. Smit, B.; Skinner, M.W. Adaptation options in agriculture to climate change: A typology. Mitig. Adapt. Strateg. Glob. Chang. 2002, 7, 85-114.

6. Adger, W.N.; Huq, S.; Brown, K.; Conway, D.; Hulme, M. Adaptation to climate change in the developing world. Prog. Dev. Stud. 2003, 3, 179-195. [CrossRef]

7. Grothmann, T.; Patt, A. Adaptive capacity and human cognition: The process of individual adaptation to climate change. Glob. Environ. Chang. 2005, 15, 199-213. [CrossRef]

8. Osbahr, H.; Twyman, C.; Adger, W.N.; Thomas, D.S.G. Evaluating successful livelihood adaptation to climate variability and change in Southern Africa. Ecol. Soc. 2010, 15, 27. [CrossRef]

9. Smit, B.; Pilifosova, O. Adaptation to climate change in the context of sustainable development and equity. In Climate Change 2001: Impacts, Adaptation and Vulnerability; McCarthy, J.J., Canziani, O.F., Leary, N.A., Dokken, D.J., White, K.S., Eds.; Cambridge University Press: Cambridge, UK, 2003; pp. 877-912.

10. Bryan, E.; Deressa, T.T.; Gbetibouo, G.A.; Ringler, C. Adaptation to climate change in Ethiopia and South Africa: Options and constraints. Environ. Sci. Policy 2009, 12, 413-426. [CrossRef]

11. Thomas, D.S.G.; Twyman, C.; Osbahr, H.; Hewitson, B. Adaptation to climate change and variability: Farmer responses to intra-seasonal precipitation trends in South Africa. Clim. Chang. 2007, 83, 301-322. [CrossRef] 
12. Ziervogel, G.; Bharwani, S.; Downing, T.E. Adapting to climate variability: Pumpkins, people and policy. Nat. Resour. Forum 2006, 30, 294-305. [CrossRef]

13. Esham, M.; Garforth, C. Agricultural adaptation to climate change: Insights from a farming community in Sri Lanka. Mitig. Adapt. Strateg. Glob. Chang. 2013, 18, 535-549. [CrossRef]

14. Howden, M.S.; Soussana, J.F.; Tubiello, F.N.; Chhetri, N.; Dunlop, M.; Meinke, H. Adapting agriculture to climate change. Proc. Natl. Acad. Sci. USA 2007, 104, 19691-19696. [CrossRef] [PubMed]

15. Acquah, D.G.; Onumah, E.E. Farmers perception and adaptation to cimate change: An estimation of willingness to pay. J. Sustain. Dev. Afr. 2011, 3, 31-39.

16. Aemro, T.; Jemma, H.; Mengistu, K. Climate change adaptation strategies of smallholder farmers: The case of Babilie District, East Harerghe Zone of Oromia Regional State of Ethiopia. J. Econ. Sustain. Dev. 2012, 3, 1-13.

17. Deressa, T.; Rashid, M.H.; Claudia, R.; Tekie, A.; Mahmud, Y. Determinants of farmers' choice of adaptation methods to climate change in the Nile Basin of Ethiopia. Glob. Environ. Chang. 2009, 19, 248-255. [CrossRef]

18. Deressa, T.; Hassan, R.M.; Ringler, C. Perception of and adaptation to climate change by farmers in the Nile basin of Ethiopia. J. Agric. Sci. 2011, 149, 23-31.

19. Hassan, R.; Nhemachena, C. Determinants of African farmers' strategies for adapting to climate change: Multinomial choice analysis. Afr. J. Agric. Resour. Econ. 2008, 2, 83-104.

20. Kurukulasuriya, P.; Mendelsohn, R. Crop Selection: Adapting to Climate Change in Africa; No. 26; Centre for Environmental Economics and Policy in Africa: Pretoria, South Africa, 2006.

21. Below, T.B.; Mutabazi, K.D.; Kirschke, D.; Franke, C.; Sieber, S.; Siebert, R.; Tscherning, K. Can farmers' adaptation to climate change be explained by socioeconomic household-level variables? Glob. Environ. Chang. 2012, 22, 223-235. [CrossRef]

22. Gebrehiwot, T.; Veen, A.V.D. Farmers prone to drought risk: Why some farmers undertake farm-level risk-reduction measures while others not? Environ. Manag. 2015, 55, 588-602.

23. Dang, H.L.; Li, E.; Nuberg, I.; Bruwer, J. Understanding farmers' adaptation intention to climate change: A structural equation modelling study in the Mekong Delta, Vietnam. Environ. Sci. Policy 2014, 41, 11-22. [CrossRef]

24. Truelove, H.B.; Carrico, A.R.; Thabrew, L. A socio-psychological model for analyzing climate change adaptation: A case study of Sri Lankan paddy farmers. Glob. Environ. Chang. 2015, 31, 85-97. [CrossRef]

25. Genius, M.; Koundouri, P.; Nauges, C.; Tzouvelekas, V. Information transmission in irrigation technology adoption and diffusion: Social learning, extension services, and spatial effects. Am. J. Agric. Econ. 2013, 96, 328-344. [CrossRef]

26. Dang, H.L.; Li, E.; Bruwer, J. Understanding climate change adaptive behavior of farmers: An integrated conceptual framework. Int. J. Clim. Chang. Impacts Responses 2012, 3, 255-272. [CrossRef]

27. Paul, C.J.; Weinthal, E.S.; Bellemare, M.F.; Jeuland, M.A. Social capital, trust, and adaptation to climate change: Evidence from rural Ethiopia. Glob. Environ. Chang. 2016, 36, 124-138. [CrossRef]

28. Milne, S.; Sheeran, P.; Orbell, S. Prediction and intervention in health related behavior: A meta-analytic review of protection motivation theory. J. Appl. Soc. Psychol. 2000, 30, 106-143. [CrossRef]

29. Rogers, R.W. A protection motivation theory of fear appeals and attitude change. J. Psychol. 1975, 91, 93-114. [CrossRef] [PubMed]

30. Tanner, J.F.; James, B.H.; David, R.E. The protection motivation model: A normative model of fear appeals. J. Mark. 1991, 55, 36-45. [CrossRef]

31. Kantola, S.J.; Syme, G.J.; Nesdale, A.R. The effects of appraised severity and efficacy in promoting water conservation: An informational analysis. J. Appl. Soc. Psychol. 1983, 13, 164-182. [CrossRef]

32. Wolf, S.; Gregory, W.L.; Stephan, W.G. Protection motivation theory: Prediction of intentions to engage in antinuclear war behavior. J. Appl. Soc. Psychol. 1986, 16, 310-321. [CrossRef]

33. Bubeck, P.; Botzen, W.J.W.; Kreibich, H.; Aerts, J.C.J.H. Detailed insights into the influence of flood-coping appraisals on mitigation behaviour. Glob. Environ. Chang. 2013, 23, 1327-1338. [CrossRef]

34. Grothmann, T.; Reusswig, F. People at risk of flooding: Why some residents take precautionary action while others do not. Nat. Hazard. 2006, 38, 101-120. [CrossRef]

35. Martin, I.M.; Bender, H.; Raish, C. What motivates individuals to protect themselves from risks: The case of wildland fires. Risk Anal. 2007, 27, 887-900. [CrossRef] [PubMed] 
36. Matuschke, I. Evaluating the Impact of Social Network in Rural Innovation Systems: An Overview. Available online: http:/ / www.ifpri.org/publication/evaluating-impact-social-networks-rural-innovation-systems (accessed on 8 March 2017).

37. Bandiera, O.; Rasul, I. Social network and technology adoption in Northern Mozambique. Econ. J. 2006, 116, 869-902. [CrossRef]

38. Baerenklau, K.A. Toward an understanding of technology adoption: Risk, learning, and neighborhood effects. Land Econ. 2005, 8, 1-19. [CrossRef]

39. Conley, T.G.; Udry, C. Social learning through networks: The adoption of new agricultural technologies in Ghana. Am. J. Agric. Econ. 2001, 83, 668-673. [CrossRef]

40. Matuschke, I.; Mishra, R.R.; Qaim, M. Adoption and impact of hybrid wheat in India. World Dev. 2007, 35, 1422-1435. [CrossRef]

41. Sherchan, W.; Nepal, S.; Paris, C. A survey of trust in social network. ACM Comput. Surv. 2013, 45, 115-123. [CrossRef]

42. Nepal, S.; Sherchan, W.; Paris, C. Building trust communities using social trust. In Proceedings of the International Conference on User Modeling, Adaptation, and Personalization, Girona, Spain, 11-15 July 2011; pp. 841-846.

43. Akpalu, W.; Arndt, C.; Matshe, I. Introduction to the Special Issue on the Economics of Climate Change Impacts on Developing Countries: Selected Studies on Sub-Saharan Africa and South-East Asia. Sustainability 2015, 7, 12122-12126. [CrossRef]

44. Jiang, R.; Xie, J.; He, H.; Luo, J.; Zhu, J. Use of four drought indices for evaluating drought characteristics under climate change in Shaanxi, China: 1951-2012. Nat. Hazard. 2015, 75, 2885-2903. [CrossRef]

45. Arthur, D.; Quester, P. Who's afraid of that ad? Applying segmentation to the protection motivation model. Psychol. Mark. 2004, 21, 671-696. [CrossRef]

46. Maddux, J.E.; Rogers, R.W. Protection motivation and self-efficacy: A revised theory of fear appeals and attitude change. J. Exp. Soc. Psychol. 1983, 19, 469-479. [CrossRef]

47. Floyd, D.L.; Prentice-Dunn, S.; Rogers, R.W. A meta-analysis of research on protection motivation theory. J. Appl. Soc. Psychol. 2000, 30, 407-429. [CrossRef]

48. Wang, G.L.; Lu, Q. The test of U-type relationship between the social network's impact and the farmers' technology adoption-Case of adoption of water saving irrigation technology in Minqin, Gansu. J. Agrotech. Econ. 2015, 92-106. (In Chinese).

49. Feng, X.L.; Chen, Z.X.; Huo, X.X. Influencing factors of apple farmer adaptation to meteorological disasters. Resour. Sci. 2015, 37, 2491-2500. (In Chinese).

50. Feng, X.L.; Chen, Z.X.; Huo, X.X. Factors influencing farmers adapting behavior to drought: Based on 1079 apple household survey data. J. AridLand Resour. Environ. 2016, 30, 43-49. (In Chinese).

51. McKenzie, K.; Gow, K. Exploring the first year academic achievement of school leavers and mature-age students through structural equation modelling. Learn. Individ. Differ. 2004, 14, 107-123. [CrossRef]

52. Hair, J.F.J.; Black, W.C.; Babin, B.J.; Anderson, R.E. Multivariate Data Analysis, 7th ed.; Prentice Hall: Upper Saddle River, NJ, USA, 2010.

53. Veen, R.V.D.; Song, H.Y. Impact of the perceived image of celebrity endorsers on tourists' intentions to visit. J. Travel Res. 2014, 53, 211-224.

54. Chan, F.; Lee, G.K.; Lee, E.J.; Kubota, C.; Allen, C.A. Structural equation modeling in rehabilitation counseling research. Rehabil. Couns. Bull. 2007, 51, 44-57.

55. Lee, S.; Scott, D.; Kim, H. Celebrity fan involvement and destination perceptions. Ann. Tour. Res. 2008, 35, 809-832. [CrossRef]

56. Bollen, K. Structural Equation with Latent Variable; Wiley \& Sons: New York, NY, USA, 1989.

(C) 2017 by the authors. Licensee MDPI, Basel, Switzerland. This article is an open access article distributed under the terms and conditions of the Creative Commons Attribution (CC BY) license (http:/ / creativecommons.org/licenses/by/4.0/). 